\title{
Different methods for separating diffuse and direct components of solar radiation and their application in crop growth models
}

\author{
Marco Bindi ${ }^{1}$, Francesco Miglietta ${ }^{2}$, Gaetano Zipoli ${ }^{2}$ \\ ${ }^{1}$ Department of Agronomy and Crop Production, University of Florence, P. le delle Cascine 18, I-50144 Firenze, Italy \\ ${ }^{2}$ IATA-CNR, Institute of Environmental Analysis and Remote Sensing for Agriculture, P. Ie delle Cascine 20, \\ I-50144 Firenze, Italy
}

\begin{abstract}
Influence of the diffuse proportion of solar radiation on the simulation of gross assimilation and dry matter production in leaf canopies is evaluated under different climatic conditions. Four methods to estimate daily and hourly values of direct and diffuse radiation from measurements of global radiation are compared both in terms of accuracy of incoming solar component estimates and of their suitability for incorporation into 2 wheat growth-simulation models (NWHEAT and SUCROS 90). Comparison showed that (1) the accuracy of direct and diffuse component estimates tends to decrease with increasing temporal resolution and varies under different climatic conditions and (2) the final grain yield calculated by the models is slightly but significantly influenced by the method used to calculate the components of incoming radiation.
\end{abstract}

\section{INTRODUCTION}

Assimilation of crop canopies depends on $\mathrm{CO}_{2}$ concentration, radiant solar energy, assimilatory capacity of the leaves and on factors that condition the distribution of solar radiation over the leaves (De Wit 1965). The ratio between diffuse and direct radiation is one of these factors and is more important than, for example, the leaf angle distribution of the canopy (Goudriaan 1977). For a given value of solar radiation an increase in the diffuse component improves the distribution of light over the canopy and crop assimilation rate increases (Goudriaan 1977).

In some crop growth models, partitioning of global radiation into its diffuse and direct components is tackled by assuming the sky to be either clear or overcast (de Wit et al. 1978, Van Keulen et al. 1982, Ng \& Loomis 1984). However, Spitters et al. (1986) indicate that this approach is not justified and Lantinga (1985) noted that it may underestimate the diffuse fraction of the incoming radiation.

Two methods to estimate the diffuse and direct radiation component based upon different principles have been proposed. The method used by Lantinga (1985) and Weiss \& Norman (1985) calculates the 2 components as a function of the potential amount of radiation that reaches the earth's surface. A second method is based on the ratio between measured global solar radiation and calculated radiation outside the atmosphere (Liu \& Jordan 1960, Collares-Pereira \& Rabl 1979, De Jong 1980, Erbs et al. 1982). Performance analysis of different formulae was recently carried out by Becker \& Weingarten (1991).

In this paper, some of the available procedures to calculate hourly and daily values of direct and diffuse solar radiation for 4 weather stations differing in geographic location and climatic conditions are compared. Calculated values are compared with actual measurements and resulting differences are evaluated statistically. Subsequently, values of solar radiation components calculated with the different methods are used as input for 2 wheat growth models (NWHEAT and SUCROS 90) and calculated grain yields are compared.

\section{MATERIALS AND METHODS}

Algorithms description. Collares-Pereira \& Rabl (1979) (Method CO) and Erbs et al. (1982) (Method ER) calculated the relationship between the diffuse fraction and atmospheric transmission of solar radiation for 
daily and hourly values respectively, while De Jong (1980) (Methods DJd and DJh) calculated the relationships for both daily and hourly values.

Relationships between the diffuse fraction of global radiation $\left(S_{\mathrm{df}} / S_{\mathrm{g}}\right)$ and atmospheric transmission $\left(S_{g} / S_{0}\right.$, where $S_{0}=$ extra terrestrial radiation) used in these methods are summarized in Fig. 1 and Appendix 1. They are characterized by an approximately linear trend for transmissions ranging between 35 and $75 \%$. At low transmissions, nearly all of the incoming radiation is diffuse so that the curve bends off.

The $S_{\mathrm{d} f} / S_{g}$ values obtained by each method must be corrected to take into account the higher intensity of diffuse radiation in the direction of the sun under clear sky conditions (circumsolar radiation). This is done using the equation proposed by Klucher (1978) (Appendix 2).

Crop growth models. Two models of wheat growth were used to test the effect of method choice for calculating $S_{\mathrm{df}} / S_{\mathrm{g}}$ on estimated wheat yields, NWHEAT (Groot 1987) and SUCROS 90 (Penning de Vries \& Van Laar 1982, Rabbinge et al. 1989), which are both based upon existing theory and models of crop growth (de Wit et al. 1978, Penning de Vries \& Van Laar 1982, van Keulen \& Seligman 1987). They simulate wheat phenological development on the basis of degree-days (Porter 1984) and biomass growth as partitioned into root, stem, leaf and grain components. Crop yield, expressed as grain weight, is given as output at the end of the simulation. Solar radiation is used as a driving variable in the models to calculate potential crop photosynthesis.

The 2 models differ in the way they calculate the diffuse fraction $S_{\mathrm{df}} / S_{\mathrm{g}}$. In NWHEAT the diffuse fraction is calculated on the basis of the daily atmospheric transmission, whereas in SUCROS 90 this fraction is calculated at 3 moments during the day, in accordance with the 3 -point Gaussian integration algorithm (Goudriaan 1986).

Models were modified in this work to allow the user to choose between the methods for calculating direct and diffuse components of solar radiation (Methods DJd and CO for NWHEAT and Methods DJh and ER for SUCROS 90).

Weather data. DJ, CO and ER methods were used to estimate direct and diffuse radiation at 4 weather stations (Table 1) that widely differ in geographic location and climatic conditions. Estimates were then compared with actual measurements at each station. Diffuse radiation was measured by means of pyranometers equipped with a shadow band to exclude direct radiation from the sun. However, since the shadow band shields the sensor from a portion of diffuse radiation coming in from the sky, a correction is required. At 2 of the 4 stations (Trappes and Carpentras) diffuse radiation values were automatically corrected during
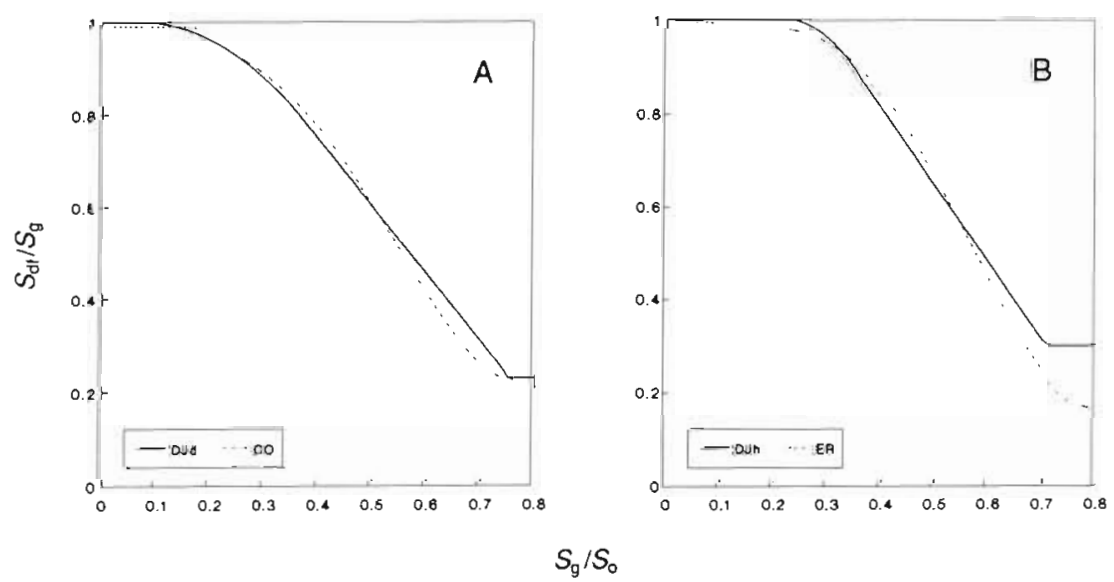

Fig. 1. Relation between diffuse fraction of global radiation $\left(S_{\mathrm{df}} / S_{\mathrm{g}}\right)$ and atmospheric transmission $\left(S_{\mathrm{g}} / S_{0}\right)$ for (A) daily and $(B)$ hourly radiation values

Table 1. Weather station locations and frequency of observations used for comparison between estimates of the diffuse fraction of solar radiation

\begin{tabular}{lll}
\hline Station & Lat. & Observation time \\
\hline Carpentras, France & $44^{\circ} 02^{\prime} \mathrm{N}$ & Daily \\
Trappes, France & $48^{\circ} 46^{\prime} \mathrm{N}$ & Daily \\
Fagna, Italy & $43^{\circ} 57^{\prime} \mathrm{N}$ & $1971-1980$ \\
Phoenix, Arizona, USA & $33^{\circ} 25^{\prime} \mathrm{N}$ & Hourly and daily \\
\end{tabular}


Table 2. Weather station location and observation year used for models application

\begin{tabular}{|lcc|}
\hline Station & Lat. & $\begin{array}{c}\text { Observation } \\
\text { years }\end{array}$ \\
\hline Swifterbant, Netherlands & $52^{\prime} 3^{\prime} 4^{\prime} \mathrm{N}$ & $1974-1980$ \\
Wageningen, Netherlands & $51^{\prime} 58^{\prime} \mathrm{N}$ & $1958-1978$ \\
Bolzano, Italy & $46^{\circ} 28^{\prime} \mathrm{N}$ & $1958-1978$ \\
Bologna, Italy & $44^{\circ} 1^{\prime} \mathrm{N}$ & $1958-1978$ \\
Vigna di Valle, Italy & $42^{\prime} 5^{\prime} \mathrm{N}$ & $1958-1978$ \\
Brindisi, Italy & $40^{\prime} 40^{\prime} \mathrm{N}$ & $1958-1978$ \\
Ustica, Italy & $38^{\circ} 45^{\prime} \mathrm{N}$ & $1958-1978$ \\
\hline
\end{tabular}

acquisition, whereas data from Phoenix and Fagna were corrected according to the method proposed by Drummond (1956) (Appendix 3).

With regard to model application, the daily weather data (global radiation, maximum and minimum tem-
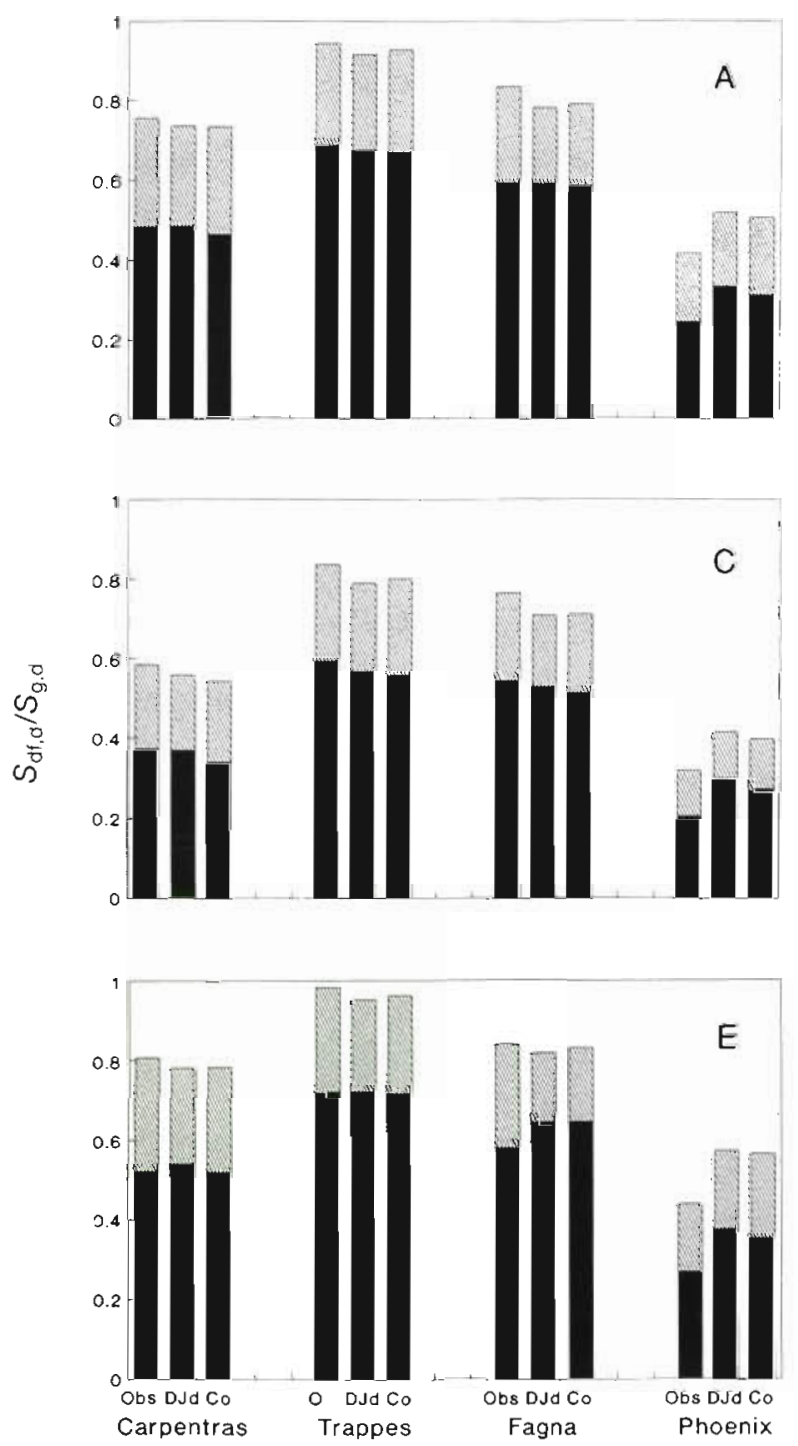

perature, rainfall, wind speed and vapour pressure) necessary to run the models were not available for stations listed in Table 1. Hence, in order to test the suitability of these methods for incorporation in growth-simulation models, the daily weather data of 7 other stations that broadly differ in climatic conditions were used (Table 2).

\section{RESULTS AND DISCUSSION}

Comparison between the calculated and measured diffuse fraction was carried out for both daily and hourly values. The mean and standard deviation (SD) of observed and estimated diffuse fractions and the mean bias error (MBE), root mean square error (rms) and correlation coefficient ( $\mathrm{r}$ ) between observed and estimated values of $S_{\mathrm{df}} / S_{\mathrm{g}}$ were calculated. Statistics of daily values were calculated for annual and seasonal (winter,
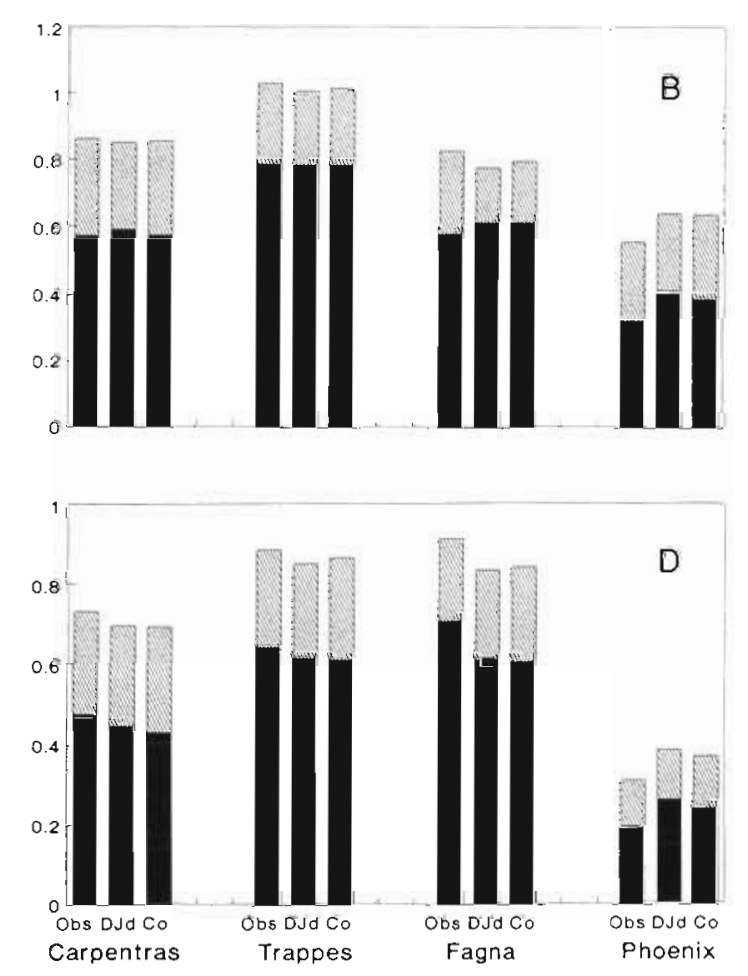

Fig. 2. Mean (solid bars) and standard deviation (hatched bars) of observed and estimated daily values of $S_{\mathrm{fli}, \mathrm{d}} / S_{\mathrm{g}, \mathrm{d}}$ for annual and seasonal periods. (A) Year; (B) winter; (C) summer; (D) spring; (E) fall. Note difference in scale for $(B)$ 

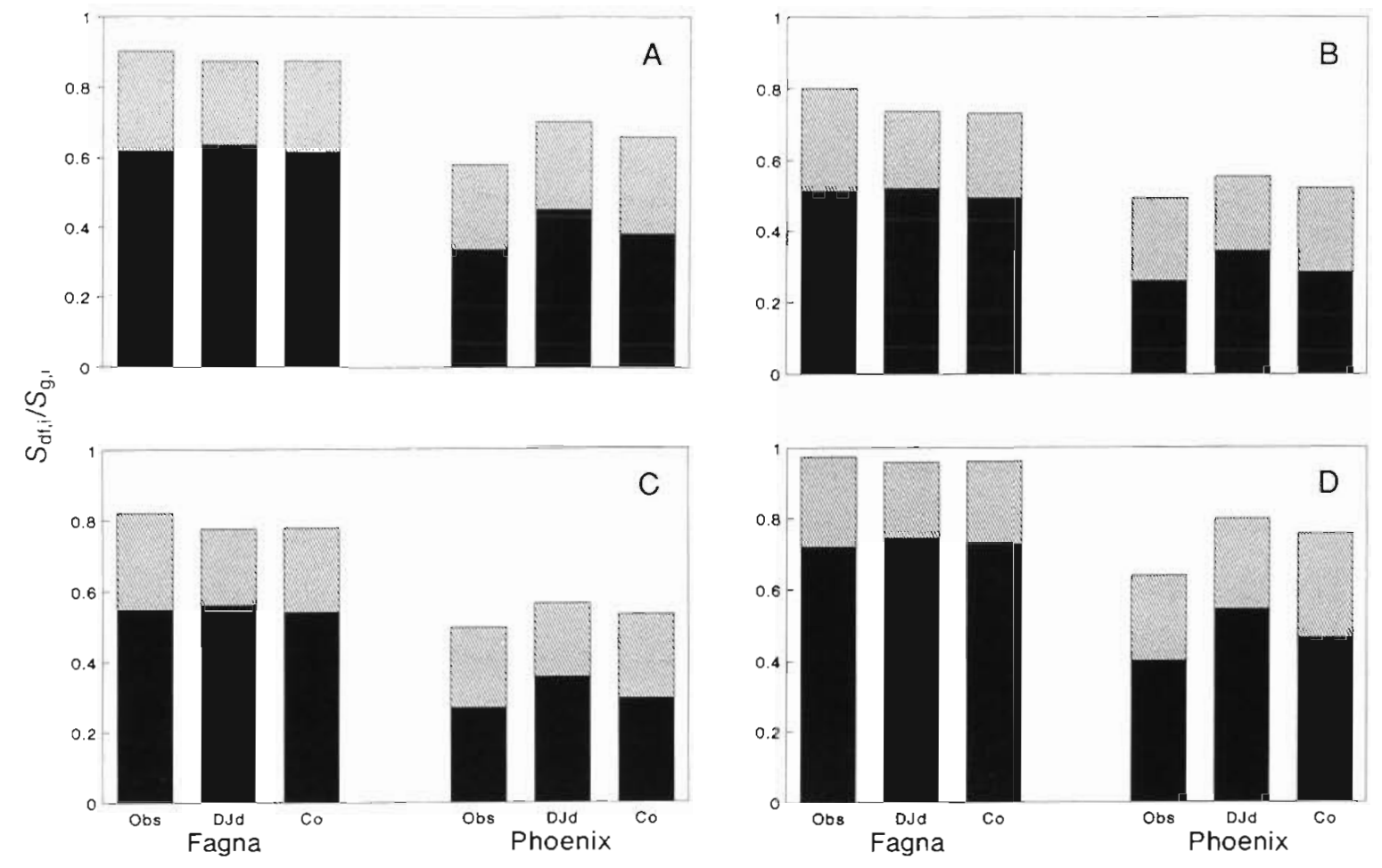

Fig. 3. Mean (solid bars) and standard deviation (hatched bars) of observed and estimated hourly values of $S_{\mathrm{ct}, \mathrm{i}} / S_{\mathrm{g}, \mathrm{i}}$ at different periods of the day. (A) Day; (B) peak; (C) medium; (D) low

spring, summer, fall) periods, whereas those of hourly values were calculated for different periods of the day: all daytime hours, peak radiation (11:00 to 13:00 h), moderate radiation (09:00 to $11: 00,13: 00$ to $15: 00 \mathrm{~h})$ and low radiation hours $(07: 00$ to $09: 00,15: 00$ to $17: 00 \mathrm{~h})$. Statistics used for comparison are reported in Figs. 2 \& 3 and Tables $3 \& 4$.

The mean and SD of daily and hourly values indicate that the estimated values of $S_{\mathrm{df}} / S_{\mathrm{g}}$ do not differ very much from observations in both absolute terms and variability (Figs. 2 \& 3). The MBE of daily values shows that Method DJd has a smaller bias for Stns Trappes, Carpentras and Fagna, but not for Stn Phoenix (Table 3). The MBE of hourly values indicate that calculated values are overestimated for Stn Phoenix and that Method DJh has the highest bias in general (Table 4). The rms values show a small variation of predicted values around the measured values for all the methods (Tables $3 \& 4$ ). The r values indicate that there is not much scattering between observed and estimated values (Tables $3 \& 4$ ). All statistical tests indicate that the accuracy of $S_{\mathrm{df}} / S_{\mathrm{g}}$ estimates is almost independent of the season and of the hour of the day, and accuracy is higher for daily than for hourly values.

Both methods proposed by De Jong (1980) and Collares-Pereira \& Rabl (1979) may be successfully used to estimate daily values of direct and diffuse radiation
(Fig. 2, Table 3), although the difference between the methods increases with decreasing $S_{\mathrm{df}, \mathrm{d}} / S_{\mathrm{g}, \mathrm{d}}$ (Fig. 4). On the other hand, estimates of hourly values of diffuse radiation obtained by the method proposed by Erbs et al. (1982) are more accurate for the data set tested (Fig. 3, Table 4). Estimates obtained by Method DJh are consistently larger than both observations and values calculated by Method ER. This difference increases with decreasing $S_{\mathrm{df}, \mathrm{i}} / S_{\mathrm{g}, 1}$ (Fig. 5). This probably depends on the differences in atmospheric conditions (relative sunshine duration, water content of the atmosphere, cloud type, etc.) of the original data set used to parameterize the 2 algorithms. Data sets for The Netherlands were used to parameterize De Jong's method, whereas Erbs's method was parameterized using weather data recorded at stations in the southern USA (Erbs et al. 1982).

Models NWHEAT and SUCROS 90 were run twice using weather data recorded at each of the 7 stations listed in Table 2. In the 2 runs, Methods DJd and CO and Methods DJh and ER, respectively, were used. Results of simulations performed with the models are illustrated in Table 5.

The mean absolute and relative differences between Methods DJd and CO in NWHEAT were $0.063 \mathrm{t} \mathrm{ha}^{-1}$ and $0.95 \%$ respectively. These differences are not large and they remained almost constant among stations (Fig. 6). 
Table 3. Mean bias error (MBE), root mean square error ( $\mathrm{rms}$ ) and correlation coefficient ( $\mathrm{r}$ ) computed in the comparison between observed and estimated daily, values of $S_{\mathrm{dt}, \mathrm{d}} / S_{\mathrm{c}, \mathrm{d}}$ ratio for annual and seasonal periods. DJd: Daily method of De Jong (1980): CO: method of Collares-Pereira \& Rabl (1979)

\begin{tabular}{|c|c|c|c|c|c|c|c|}
\hline \multirow[t]{2}{*}{ Method } & \multicolumn{3}{|c|}{ Statistical tests } & \multirow[t]{2}{*}{ Method } & \multicolumn{3}{|c|}{ Statistical tests } \\
\hline & $\mathrm{MBE}$ & $\mathrm{rms}$ & $r$ & & MBE & rms & $r$ \\
\hline Year & & & & Fagna, Italy & & & \\
\hline Carpentras, France & & & & DJd & 0.016 & 0.142 & 0.757 \\
\hline DJd & 0.000 & 0.086 & 0.948 & $\mathrm{CO}$ & 0.030 & 0.146 & 0.759 \\
\hline $\mathrm{CO}$ & 0.020 & 0.088 & 0.949 & Phoenix, Arizona, USA & & & \\
\hline Trappes, France & & & & DJd & -0.096 & 0.116 & 0.841 \\
\hline DJd & 0.013 & 0.080 & 0.951 & $\mathrm{CO}$ & -0.068 & 0.099 & 0.826 \\
\hline $\mathrm{CO}$ & 0.018 & 0.082 & 0.952 & & & & \\
\hline Fagna, Italy & & & & Spring & & & \\
\hline DJd & 0.000 & 0.153 & 0.765 & Carpentras, France & & & \\
\hline $\mathrm{CO}$ & 0.007 & 0.154 & 0.766 & DJd & 0.029 & 0.086 & 0.948 \\
\hline Phoenix, Arizona, USA & & & & $\mathrm{CO}$ & 0.048 & 0.100 & 0.943 \\
\hline DJd & -0.089 & 0.110 & 0.936 & Trappes, France & & & \\
\hline $\mathrm{CO}$ & -0.067 & 0.097 & 0.934 & DJd & 0.026 & 0.081 & 0.948 \\
\hline & & & & $\mathrm{CO}$ & 0.032 & 0.086 & 0.949 \\
\hline $\begin{array}{l}\text { Winter } \\
\text { Carpentras, France }\end{array}$ & & & & Fagna, Italy & & & \\
\hline DJd & -0.018 & 0.089 & 0.955 & $\breve{D J d}$ & 0.097 & 0.181 & 0.736 \\
\hline $\mathrm{CO}$ & -0.001 & 0.083 & 0.958 & $\mathrm{CO}$ & 0.102 & 0.189 & 0.737 \\
\hline Trappes, France & & & & Phoenix, Arizona, USA & & & \\
\hline DJd & 0.001 & 0.073 & 0.953 & DJd & -0.066 & 0.075 & 0.957 \\
\hline $\mathrm{CO}$ & 0.003 & 0.073 & 0.952 & $\mathrm{CO}$ & -0.049 & 0.066 & 0.936 \\
\hline Fagna, Italy & & & & Fall & & & \\
\hline DJd & -0.035 & 0.146 & 0.825 & Carpentras, France & & & \\
\hline $\mathrm{CO}$ & -0.035 & 0.138 & 0.840 & DJd & -0.018 & 0.094 & 0.951 \\
\hline Phoenix, Arizona, USA & & & & $\mathrm{CO}$ & 0.002 & 0.084 & 0.956 \\
\hline DJd & -0.084 & 0.097 & 0.977 & Trappes, France & & & \\
\hline $\mathrm{CO}$ & -0.065 & 0.085 & 0.977 & DJd & -0.003 & 0.080 & 0.956 \\
\hline Summer & & & & $\mathrm{CO}$ & 0.000 & 0.076 & 0.957 \\
\hline Carpentras, France & & & & Fagna, Italy & & & \\
\hline DJd & 0.004 & 0.075 & 0.936 & DJd & -0.064 & 0.151 & 0.874 \\
\hline $\mathrm{CO}$ & 0.032 & 0.085 & 0.928 & $\mathrm{CO}$ & -0.063 & 0.146 & 0.874 \\
\hline Trappes, France & & & & Phoenix, Arizona, USA & & & \\
\hline DJd & 0.026 & 0.087 & 0.939 & DJd & -0.108 & 0.138 & 0.900 \\
\hline $\mathrm{CO}$ & 0.036 & 0.090 & 0.941 & $\mathrm{CO}$ & -0.086 & 0.125 & 0.902 \\
\hline
\end{tabular}

Table 4. Mean bias error (MBE), root mean square error (rms) and correlation coefficient (r) computed in the comparison between observed and estimated hourly value of $S_{\mathrm{d} f, 1} / S_{\mathrm{g}, \mathrm{i}}$ ratio at different periods of the day. DJh: Hourly method of De Jong (1980); ER: method of Erbs et al. (1982)

\begin{tabular}{|c|c|c|c|c|c|c|c|}
\hline \multirow[t]{2}{*}{ Method } & \multicolumn{3}{|c|}{ Statistical tests } & \multirow[t]{2}{*}{ Method } & \multicolumn{3}{|c|}{ Statistical tests } \\
\hline & MBE & $\mathrm{rms}$ & I & & MBE & rms & r \\
\hline Day & & & & Medium & & & \\
\hline Fagna, Italy & & & & Fagna, Italy & & & \\
\hline DJh & -0.017 & 0.152 & 0.848 & DJh & -0.013 & 0.147 & 0.848 \\
\hline ER & 0.002 & 0.158 & 0.836 & $\mathrm{ER}$ & 0.006 & 0.144 & 0.850 \\
\hline Phoenix, Arizona, USA & & & & Phoenix, Arizona, USA & & & \\
\hline DJh & -0.117 & 0.170 & 0.877 & DJh & -0.087 & 0.136 & 0.888 \\
\hline ER & -0.046 & 0.153 & 0.855 & $\mathrm{ER}$ & -0.027 & 0.108 & 0.899 \\
\hline Peak & & & & Low & & & \\
\hline Fagna, Italy & & & & Fagna, Italy & & & \\
\hline DJh & -0.007 & 0.158 & 0.838 & DJh & -0.025 & 0.152 & 0.810 \\
\hline ER & 0.019 & 0.153 & 0.848 & $\mathrm{ER}$ & 0.009 & 0.167 & 0.769 \\
\hline Phoenix, Arizona, USA & & & & Phoenix, Arizona, USA & & & \\
\hline DJh & -0.084 & 0.133 & 0.899 & DJh & -0.146 & 0.197 & 0.856 \\
\hline ER & -0.026 & 0.105 & 0.908 & ER & -0.065 & 0.185 & 0.803 \\
\hline
\end{tabular}




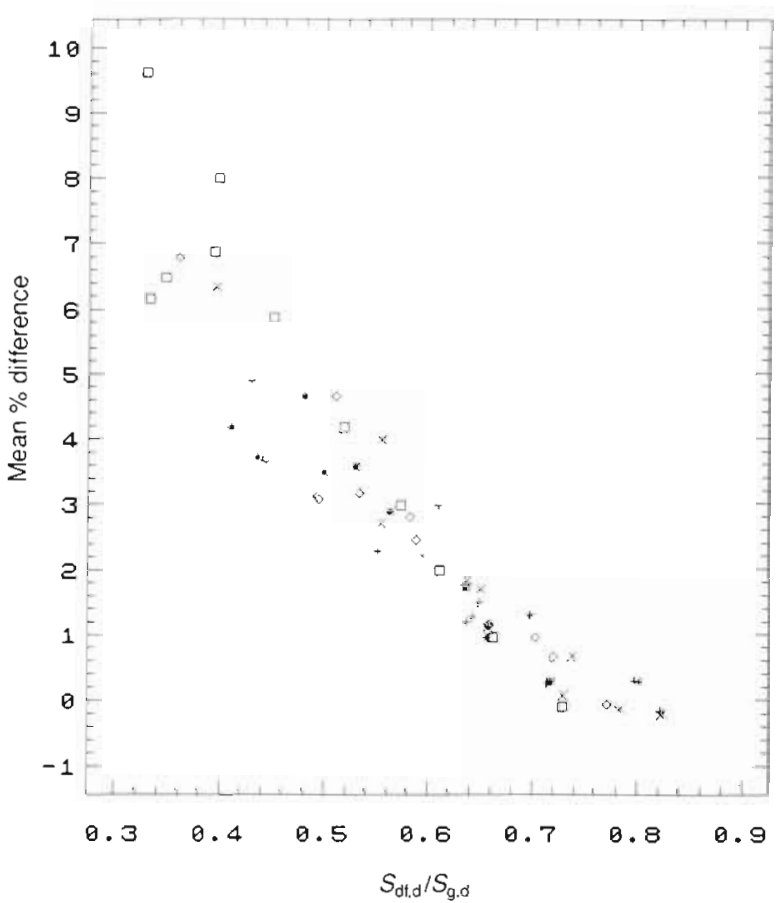

Fig. 4. Mean percent difference between daily values of diffuse radiation obtained by Methods DJd and Co vs mean $S_{\text {difd }} / S_{\text {g,d }}$ calculated for the whole year and for different seasons for stations listed in Tables $1 \& 2,(+1$ Winter; (*) spring; () summer $_{i}(x)$ fall; $(\diamond)$ year

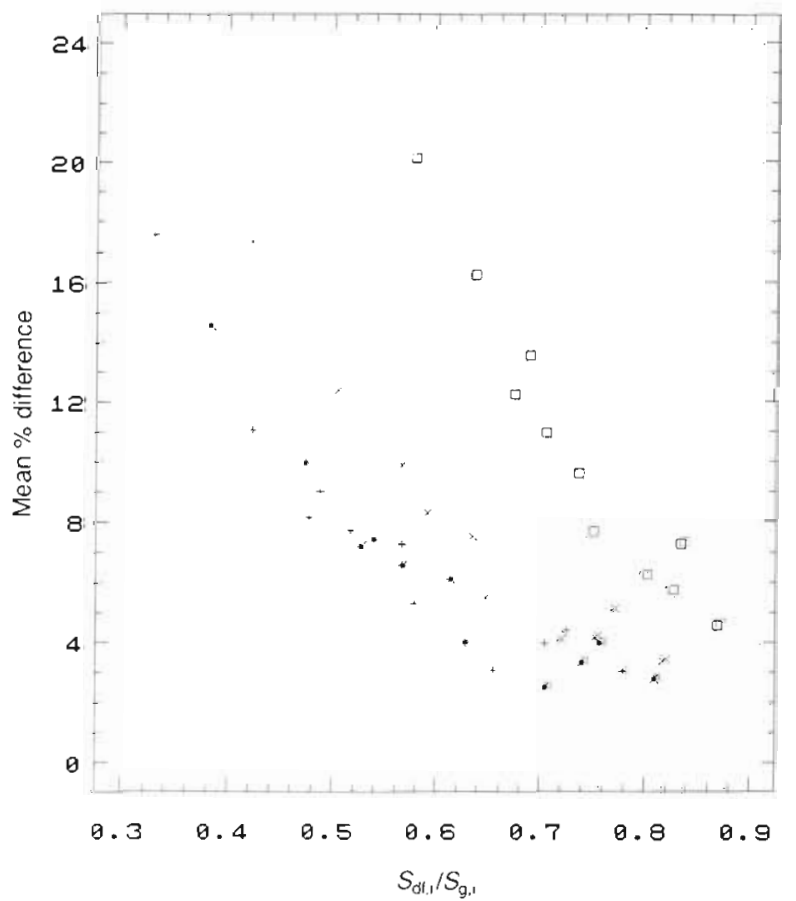

Fig. 5. Mean percent different between hourly values of diffuse radiation obtained by Methods DJh and ER vs mean $S_{\mathrm{dt},} / S_{\mathrm{y}, 1}$ calculated for the whole day and for the different periods of day for stations listed in Tables 1. \& 2. (+) Peak; (*) medium; ( $($ ) low; (x) day
Table 5. Mean absolute and relative difference calculated between wheat yield predictions obtained by the use of different methods for separating direct and diffuse components of solar radiation

\begin{tabular}{|lcc}
\hline Station & $\begin{array}{c}\text { Absolute } \\
\text { difference } \\
\left(\text { t ha }^{-1}\right)\end{array}$ & $\begin{array}{c}\text { Relative } \\
\text { difference } \\
(\%)\end{array}$ \\
\hline DJd - CO methods (Model NWHEAT) & \\
Swifterbant, Netherlands & 0.058 & 0.73 \\
Wageningen, Netherlands & 0.084 & 1.20 \\
Bolzano, Italy & 0.075 & 1.27 \\
Bologna, Italy & 0.051 & 0.92 \\
Vigna di Valle, Italy & 0.046 & 0.71 \\
Brindisi, Italy & 0.053 & 0.80 \\
Ustica, Italy & 0.071 & 1.05 \\
DJh - ER methods (Model SUCROS & $90)$ & \\
Swifterbant, Netherlands & 0.068 & 0.83 \\
Wageningen, Netherlands & 0.048 & 0.67 \\
Bolzano, Italy & 0.228 & 2.23 \\
Bologna, Italy & 0.144 & 2.52 \\
Vigna di Valle, Italy & 0.200 & 2.68 \\
Brindisi, Italy & 0.211 & 3.07 \\
Ustica, Italy & 0.383 & 4.40 \\
\end{tabular}

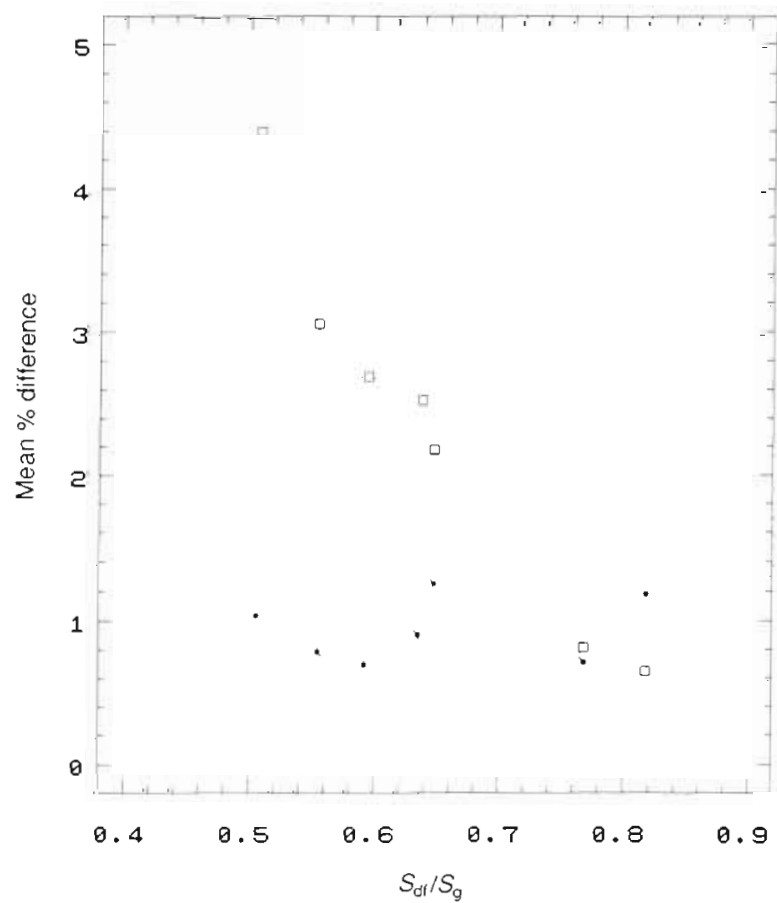

Fig. 6. Mean percent difference between wheat yields calculated with (*) Methods DJd and Co in Model NWHEAT and (D) with Methods DJh and ER in Model SUCROS 90 vs the mean fraction of diffuse radiation $\left(S_{\mathrm{di}} / S_{\mathrm{g}}\right)$ calculated over the whole simulation period 
The mean absolute and relative differences calculated between Methods DJh and ER used in SUCROS 90 were $0.16 \mathrm{tha}^{-1}$ and $2.34 \%$ respectively. The larger diffuse fraction of radiation that is calculated by Method DJh determines a consistent increase in calculated yield; this yield is greater for stations with low values of $S_{\mathrm{df}} / S_{\mathrm{G}}$ where the differences between the 2 methods have been observed to be higher (Fig. 6).

\section{CONCLUSIONS}

There is a large inter-site variability in the relationship between diffuse and total irradiation (Becker 1987. Becker \& Weingarten 1991). Models used to estimate components of global radiation are often developed on the basis of radiation data recorded at a specific site and this makes their general use problematic. Differences between methods tend to increase with increasing temporal resolution. The difference between the observed and estimated mean monthly diffuse fraction is generally very small (Becker \& Weingarten 1991), and in this paper, we found that it also applies to daily mean values. Differences become larger when hourly values are considered, especially during peak radiation hours.

This conclusion is of practical importance when a given model for separating direct and diffuse components of global radiation has to be incorporated into a crop growth simulator. Models like SUCROS 90 that make use of estimated hourly values of the diffuse fraction for calculating canopy assimilation rates require the highest estimation accuracy. In fact, small errors in estimates may slightly but significantly influence the final yields. The separation method proposed by Erbs et al. (1982) appears to be in general more accurate than the one proposed by De Jong (1980), especially for low values of $S_{\mathrm{d} f} / S_{\mathrm{g}}$ where the latter method overestimates diffuse fraction of global radiation. The incorporation of both methods in the simulator and the possibility to interactively choose between them could be of some help for simulation studies that have to be conducted under widely different climatic conditions.

Acknowledgements. The authors thank P. J. Pinter Jr and D. Van Kraalingen for weather data, J. J. R. Groot and S. Nonhebel for the FORTRAN code of the NWHEAT and SUCROS 90 models and $G$. Maracchi for discussion.

\begin{tabular}{|c|c|c|c|c|}
\hline \multicolumn{5}{|c|}{ Appendix 1} \\
\hline Method DJd & $\begin{array}{l}\text { Daily radiation data } \\
S_{\mathrm{df,d}} / S_{\mathrm{g}, \mathrm{d}}=1 \\
S_{\mathrm{df,d}} / S_{\mathrm{g}, \mathrm{d}}=1-2.3\left(S_{\mathrm{g}, \mathrm{d}} / S_{\mathrm{odd}}-0.07\right)^{2} \\
S_{\mathrm{df,d}} / S_{\mathrm{g}, \mathrm{d}}=1.33-1.46\left(S_{\mathrm{g}, \mathrm{d}} / S_{\mathrm{o}, \mathrm{d}}\right) \\
S_{\mathrm{df}, \mathrm{d}} / S_{\mathrm{g}, \mathrm{d}}=0.23\end{array}$ & $\begin{array}{l}\text { for } S_{g, d} / \\
\text { for } 0.07 \\
\text { for } 0.35 \\
\text { for } 0.75\end{array}$ & $\begin{array}{l}<0.07 \\
g_{g, d} / S_{0, d}<0.35 \\
g, d / S_{0, d}<0.75 \\
g, d / S_{0, d}\end{array}$ & $\begin{array}{l}(1 \mathrm{a}) \\
(1 \mathrm{~b}) \\
(1 \mathrm{c}) \\
(1 \mathrm{~d})\end{array}$ \\
\hline \multicolumn{5}{|c|}{ where $S_{d r, d}, S_{g, d}$ and $S_{0, d}=$ daily diffuse, global and extra terrestrial radiation $\left(\mathrm{J} \mathrm{m}^{-2} \mathrm{~d}^{-1}\right)$ respectively } \\
\hline \multirow[t]{2}{*}{ Method DJh } & 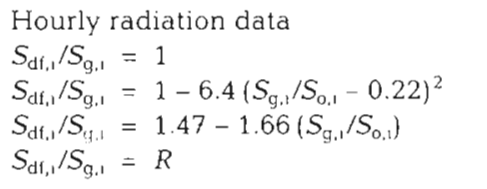 & $\begin{array}{l}\text { for } S_{g, 1} / S \\
\text { for } 0.22 \\
\text { for } 0.35 \\
\text { for } K<\end{array}$ & $\begin{array}{l}0.22 \\
{ }_{g, i} / S_{0,1} \leq 0.35 \\
{ }_{g, 1} / S_{0,1} \leq K \\
S_{0, i}\end{array}$ & $\begin{array}{l}(2 \mathrm{a}) \\
(2 \mathrm{~b}) \\
(2 \mathrm{c}) \\
(2 \mathrm{~d})\end{array}$ \\
\hline & \multicolumn{3}{|l|}{$\begin{array}{l}R=0.847-1.61(\sin \beta)+1.04\left(\sin ^{2} \beta\right) \\
K=(1.47-R) / 1.66\end{array}$} & $\begin{array}{r}(2 \mathrm{e}) \\
(2 \mathrm{f})\end{array}$ \\
\hline \multicolumn{5}{|c|}{$\begin{array}{l}\text { where } S_{\mathrm{d}, \mathrm{i},} S_{\mathrm{g}, \mathrm{l}} \text { and } S_{\mathrm{o}, \mathrm{i}}=\text { diffuse, global and extra terrestrial radiation }\left(\mathrm{J} \mathrm{m}^{-2} \mathrm{~h}^{-1}\right) \text { respectively and } \beta=\text { angle } \\
\text { of the sun above the horizon (degrees) }\end{array}$} \\
\hline Method CO & \multicolumn{2}{|c|}{$\begin{aligned} & \text { Daily radiation data } \\
& S_{\mathrm{d} ! \mathrm{d}} / S_{\mathrm{gl,d}}= 0.99 \\
& S_{\mathrm{d}, \mathrm{d}} / S_{\mathrm{g}, \mathrm{d}}= 1.188-2.272\left(S_{\mathrm{g}, \mathrm{d}} / S_{\mathrm{o}, \mathrm{d}}\right)+9.473\left(S_{\mathrm{g}, \mathrm{d}} / S_{\mathrm{odd}}\right)^{2} \\
&-21.856\left(S_{\mathrm{g}, \mathrm{d}} / S_{0, \mathrm{~d}}\right)^{3}+14.648\left(S_{\mathrm{g}, \mathrm{d}} / S_{\mathrm{o}, \mathrm{d}}\right)^{4} \\
& S_{\mathrm{d}, \mathrm{d}} / S_{\mathrm{g}, \mathrm{d}}= 0.25\end{aligned}$} & $\begin{array}{l}\text { for } S_{\mathrm{g}, \mathrm{d}} / S_{0, \mathrm{~d}} \leq 0.17 \\
\text { for } 0.17<S_{\mathrm{g}, \mathrm{d}} / S_{\mathrm{o}, \mathrm{d}} \leq 0.80 \\
\text { for } S_{\mathrm{g} . \mathrm{d}} / S_{0, \mathrm{~d}}>0.80\end{array}$ & $\begin{array}{l}(3 a) \\
(3 b) \\
(3 c)\end{array}$ \\
\hline Method ER & \multicolumn{2}{|c|}{ 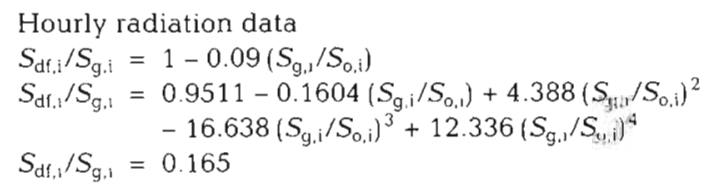 } & $\begin{array}{l}\text { for } S_{\mathrm{g}, \mathrm{i}} / S_{0.1} \leq 0.22 \\
\text { for } 0.22<S_{\mathrm{g}, 1} / S_{0,1} \leq 0.80 \\
\text { for } S_{\mathrm{g}, 1} / S_{0, \mathrm{i}} \leq 0.80\end{array}$ & $\begin{array}{l}(4 a) \\
(4 b) \\
(4 c)\end{array}$ \\
\hline
\end{tabular}




\section{Appendix 2}

The diffuse fraction adjusted for circumsolar radiation is obtained as follows:

$$
S_{\mathrm{di}}^{\prime} / S_{\mathrm{g}}=\left(S_{\mathrm{df}} / S_{\mathrm{g}}\right) /\left[1+\left(1-\left(S_{\mathrm{di}} / S_{\mathrm{g}}\right)^{2}\right) \sin ^{2} \beta \cos ^{3} \beta\right]
$$

\section{Appendix 3}

In the method proposed by Drummond (1956) a correction multiplicative coefficient $K$ is calculated as a function of the fraction of diffuse radiation shielded by the shadow band $(X)$ which is given by the following equation:

$$
X=\frac{2 b}{\pi r} \cos ^{3} \delta\left[\left(\frac{\pi}{180} \tau_{\mathrm{s}}\right) \sin \phi \sin \delta+\cos \phi \cos \delta \cos \tau_{\mathrm{s}}\right]
$$

where $b=$ shadow band width $r=$ shadow band radius; $\delta=$ solar declination; $\phi=$ latitude in degrees; and $\tau_{\mathrm{s}}=$ azimutal angle of the sun at sunrise (degrees). Then, a factor $K^{\prime}$ for isotropic conditions is calculated as follows:

$$
K^{\prime}=\frac{1}{1-X}
$$

and the correction factor, $K_{1}$ for anisotropic conditions is given by the following relationship

$$
\begin{aligned}
& K=K^{\prime}+0.07 \text { (clear sky) } \\
& K=K^{\prime}+0.03 \text { (overcast sky) } \\
& K=K^{\prime}+0.04 \text { (partly cloudy sky) }
\end{aligned}
$$

\section{LITERATURE CITED}

Becker, P. (1987). Monthly average solar radiation in Panama - insolation daily and hourly relation between direct and global solar. Solar Energy 39: 445-453

Becker, P., Weingarten, D. S. (1991). A comparison of several models for separating direct and diffuse components of solar irradiation. Agric. For. Meteorol. 53: 347-353

Collares-Pereira, M., Rabl, A. (1979). The average distribution of solar radiation-correlations between diffuse and hemispherical and between daily and hourly insolation values. Solar Energy 22: 155-164

De Jong, J. B. R. M. (1980). Een karakterisering van de zonnestraling in Nederland. Doctor-aalverslag Vakgroep Fysiche Aspecten van de Gebouwde Omgeving afd. Bouwkunde en Vakgroep Warmte-en Stromingstechnieken afd. Werktuigbouwkunde, Technische Hogeschool (Techn. Univ.), Eindhoven, Netherlands

De Wit, C. T. (1965). Photosynthesis of leaf canopies. Agric. Res. Rep. no. 663. Pudoc, Wageningen

De Wit, C. T., and co-authors (1978). Simulation of assimilation, respiration and transpiration of crops. Simulation Monographs. Pudoc, Wageningen

Drummond, A. J. (1956). On the measurement of sky radiation. Arch. Meteorol. Geophys. Bioclimatol. Ser. B 7 (3/4)

Erbs, D. G., Klein, S. A., Duffie, J. A. (1982). Estimation of the diffuse radiation fraction for hourly, daily and monthlyaverage global radiation. Solar Energy 28: 293-302

Goudriaan, J. (1977). Crop micrometeorology: a simulation study. Simulation Monographs. Pudoc, Wageningen

Goudriaan, J. (1986). A simple and fast numerical method for the computation of daily totals of crop photosynthesis. Agric. For. Meteorol. 38: 257-262

Groot, J. J. R. (1987). Simulation of nitrogen balance in a system of winter wheat and soil. Simulation Report CABOIT No. 13, Centre for Agrobiological Research, Department of Theoretical Production Ecology, Wageningen

Editor: G. Esser
Klucher, T (1978). Evaluation of models to predict insolation on tilted surfaces. N.A.S.A., TM-78842

Lantinga, E. A. (1985). Productivity of grassland under continuous and rotational grazing. Ph.D. dissertation, Agric. Univ., Wageningen

Liu, B. Y. H., Jordan, R. C. (1960). The interrelationship and characteristic distribution of direct, diffuse and total solar radiation. Solar Energy 4: 1-19

Ng, E., Loomis, R. S. (1984). Simulation of growth and yield of the potato crop. Simulation Monographs. Pudoc, Wageningen

Penning de Vries, F. W. T., van Laar, H. H. (1982). Simulation of plant growth and crop production. Simulation Monographs. Pudoc, Wageningen

Porter, J. R. (1984). A model of canopy development in winter wheat. J. agric. Sci. Camb. 102: 382-392

Rabbinge, R., Ward, S. A., van Laar, H. H. (1988). Simulation and systems management in crop protection. Simulation Monograph Series No. 32. Pudoc, Wageningen

Spitters, C. J. T., Toussaint, H. A. J M. Goudriaan, $J$ (1986). Separating the diffuse and direct component of the global radiation and its implications for modelling canopy photosynthesis. Part I. Components of incoming radiation. Agric. For. Meteorol. 38: $217-229$

Van Keulen, G. J., Penning de Vries, F. W. T., Drees, E. M (1982). A summary model for crop growth. In: Penning de Vries, F. W. T., van Laar, H. H. (eds.) Simulation of plant growth and crop production. Simulation Monographs. Pudoc, Wageningen, p. 87-97

Van Keulen, G. J., Seligman, N. G. (1987). Simulation of water use, nitrogen nutrition and growth of a spring wheat crop. Simulation Monographs. Pudoc, Wageningen

Weiss, A., Norman, J. M. (1985). Partitioning solar radiation into direct and diffuse, visible and near-infrared compo. nents. Agric. For. Meteorol. 34: 205-213 